\title{
OPEN An innovative technique for electronic transport model of group-III nitrides
}

\author{
Anshika Srivastava ${ }^{1,2 凶}$, Anshu Saxena ${ }^{1,2}$, Praveen K. Saxena ${ }^{1}$, F. K. Gupta ${ }^{1}$, \\ Priyanka Shakya ${ }^{1}$, Pankaj Srivastava ${ }^{1}$, Manish Dixit ${ }^{2}$, S. Gambhir ${ }^{2}$, R. K. Shukla ${ }^{3}$ \&
} A. Srivastava ${ }^{3}$

An optimized empirical pseudopotential method (EPM) in conjunction with virtual crystal approximation (VCA) and the compositional disorder effect is used for simulation to extract the electronic material parameters of wurtzite nitride alloys to ensure excellent agreement with the experiments. The proposed direct bandgap results of group-III nitride alloys are also compared with the different density functional theories (DFT) based theoretical results. The model developed in current work, significantly improves the accuracy of calculated band gaps as compared to the ab-initio method based results. The physics of carrier transport in binary and ternary nitride materials is investigated with the help of in-house developed Monte Carlo algorithms for solution of Boltzmann transport equation (BTE) including nonlinear scattering mechanisms. Carrier-carrier scattering mechanisms defined through Coulomb-, piezoelectric-, ionized impurity-, surface roughnessscattering with acoustic and intervalley scatterings, all have been given due consideration in present model. The direct and indirect energy bandgap results have been calibrated with the experimental data and use of symmetric and asymmetric form factors associated with respective materials. The electron mobility results of each binary nitride material have been compared and contrasted with experimental results under appropriate conditions and good agreement has been found between simulated and experimental results.

The group-III nitride semiconductor materials possess proven outstanding properties for device applications ${ }^{1}$. The high electric breakdown voltage, thermodynamic stability, high saturation current, strong piezoelectric polarization effect make them suitable for production of light emitting diodes (LED), laser diodes ${ }^{1}$ and high power transistors $(\text { HEMT })^{2}$. Solid state lighting sources based on nitride materials have shown tremendous potential in terms of less energy consumption (upto $85 \%$ less). The ternary nitride alloys provide flexibility to enhance the device performance through tailoring the material properties by changing material contents ${ }^{1-6}$.

The non-availability of sufficient quality materials impeded the technological advancement for group-III nitride based devices ${ }^{6}$. The transport properties at low and high-field conditions and the corresponding potential for device applications are yet to be uncovered ${ }^{6}$. Computational techniques appear to be most valuable tools for better understanding of the underlying physics and transport phenomenon under non-equilibrium conditions.

The present state-of-the-art in studying electronic transport in semiconductors have evolved to the use of band structure calculated using density functional theory (DFT), carrier-phonon interactions using similar ab-initio methods, carrier-impurity scattering using sophisticated methods to account for dielectric screening ${ }^{3}$. However, the computational tool based on DFT suffers with limitations that it can be used for a very small structure of clusters of atoms. The other big limitations of DFT are that many times it doesn't correctly treat the exchange interaction and long-range non-covalent interactions ${ }^{4-8}$. Semi-empirical methods appear to be most suitable technique to address these issues. Furthermore, it can be easily extended to simulate dynamical properties of the materials ${ }^{4-11}$.

Ensemble Monte Carlo (EMC) technique is the best suited numerical approach for accurate solution of the Boltzmann equation (BTE) under nonlinear response conditions ${ }^{12-14}$. The aim of the present paper is to demonstrate a simple and inexpensive theoretical approach for prediction of the low and high field mobility model for binary and ternary wurtzite nitride alloys for entire concentration range. The full electronic band structure

\footnotetext{
${ }^{1}$ Tech Next Lab Pvt Ltd, Lucknow 226003, India. ${ }^{2}$ Sanjay Gandhi Post Graduate Institute of Medical Sciences (Deemed Univeristy), Lucknow 226014, India. ${ }^{3}$ Department of Physics, University of Lucknow, Lucknow 226007, India. ${ }^{\square}$ email: a.srivastava@technextlab.com
} 


\begin{tabular}{|l|l|l|l|}
\hline Material & $\mathbf{a}(\AA)$ & $\mathbf{c}(\AA)$ & $\mathbf{u}$ \\
\hline $\mathrm{GaN}$ & $3.189^{10}$ & $5.185^{10}$ & $0.377^{10}$ \\
\hline $\mathrm{AlN}$ & $3.110^{10}$ & $4.980^{10}$ & $0.380^{10}$ \\
\hline $\mathrm{InN}$ & $3.544^{10}$ & $5.718^{10}$ & $0.379^{10}$ \\
\hline
\end{tabular}

Table 1. Lattice constants and internal parameters of binary group-III nitrides used in the present analysis.

\begin{tabular}{|l|l|l|l|}
\hline Material & $\mathbf{A l}_{0.2} \mathbf{G a}_{0.8} \mathbf{N}$ & $\mathbf{I n}_{0.2} \mathbf{G a}_{0.8} \mathbf{N}$ & $\mathbf{I n}_{0.2} \mathbf{A l}_{0.8} \mathbf{N}$ \\
\hline Alloy disorder $(\mathrm{P})$ & $0.025^{32}$ & $0.022^{32}$ & $0.025^{32}$ \\
\hline Simulated Lattice Constant $(\AA)$ & 3.169 & 3.256 & 3.193 \\
\hline
\end{tabular}

Table 2. Optimum alloy disorder parameters used in current study and interpolated lattice constant of ternary nitrides for $x=0.2$. The lattice constant has been simulated using the formula ${ }^{9}$ $\mathrm{a}(\mathrm{ABN})=\mathrm{x} \cdot \mathrm{a}(\mathrm{AN})+(1-\mathrm{x}) \cdot \mathrm{a}(\mathrm{BN})+\mathrm{P} \cdot[\mathrm{x} \cdot(1-\mathrm{x})]^{1 / 2}$.

is simulated by EPM method (using TNL's FullBand simulator) for better understanding of the structural and electronic properties ${ }^{15}$. TNL's FullBand Simulator is powerful tool to simulate full electronic band structures of semiconductors with the zincblende as well as wurtzite structures ${ }^{15}$.

The carrier transport properties including multiple appropriate scattering mechanisms ${ }^{12-16}$ associated with nitride alloys have been simulated by the solution of BTE through EMC method (using TNL's ElecMob simulator $)^{12-17}$. ElecMob simulator is capable to simulate carriers transport on full energy band including random scattering events due to impurities, lattice vibrations, etc. ${ }^{17}$. The difference in present analysis from earlier reported results is attributed to using optimized band structures and estimation of electron mobility based on different scattering mechanisms. Various scattering processes included in present analysis are-acoustic, intervalley, optical (Polar), piezoelectric, ionized impurity, Coulomb, surface roughness ${ }^{16}$.

The calculations of electronic band structure parameters are important prerequisite for the Monte Carlo method used here. We are presenting solution to address successfully the carrier transport in III-V wurtzite alloys using the Tech Next Lab's, TNL's ElecMob simulator ${ }^{17}$. For this the full electronic band structure has been calculated, using TNL's FullBand simulator, from which different physical parameters have been determined. The electronic and optical properties extracted from full band structure are used as input parameters for obtaining solution of BTE which is required for simulation of carrier transport under external applied forces on the three valleys $\Gamma_{\mathrm{c}}^{1}$, $\mathrm{U}$ and $\Gamma_{\mathrm{c}}^{3}$. The proposed mobility model is calibrated against the reported experimental/theoretical results along with calibration of selected electronic structure parameters.

\section{Numerical technique}

Empirical pseudopotential method (EPM) is able to provide behavior of electrons on full electronic band structures of the crystals with spin-orbit interactions and also provides flexibility to fit experimental transport data. The reliable description of the density of states (DOS) makes this method superior approach over the k.p and tight binding methods ${ }^{18}$.

The effective single-particle Schrödinger equation is ${ }^{13}$,

$$
-\frac{\hbar^{2}}{2 \mathrm{~m}^{*}} \vec{\nabla}^{2} \psi(\mathrm{r})+\left[\mathrm{V}^{\mathrm{c}}(\mathrm{r})+\mathrm{V}^{\mathrm{e}}(\mathrm{r})\right]=\mathrm{E} \psi(\mathrm{r})
$$

Here $V^{c}(r)$ and $V^{e}(r)$ demonstrate about the intrinsic crystal potential, and the extrinsic potential respectively. In proposed model, the crystal potential is chosen by local atomistic empirical pseudopotentials of each atom $\alpha^{13}$,

$$
\mathrm{V}^{\mathrm{c}}(\mathbf{r})=\sum_{\alpha} \mathrm{V}^{\alpha}\left(\left|\mathbf{r}-\mathbf{R}_{\alpha}\right|\right)
$$

Here $V_{\alpha}$ is the radial empirical pseudopotential of $\alpha$ th atom centered at $\mathbf{R}_{\alpha}$ as taken in reference ${ }^{13}$.

The electronic band structures of the binary wurtzite compounds are simulated using lattice parameters obtained from XRD studies as depicted in Table 1. The lattice constants of ternary alloys are computed through interpolation of lattice constants of binary alloys with inclusion of virtual crystal approximation (VCA) techniques $^{9-11}$. The selected band parameters are matched with the reported band parameters for different mole fraction of ternary alloys. The energy band gap values at gamma valley, simulated using only interpolated lattice constants 'a' of associated binary alloys for ternary are shown in Table 2. Different researchers have taken different values of bowing parameters for calibration of band gap parameter ${ }^{19-22}$. It is important to mention here that previous results have been reported using interpolation of energy band gap of binary nitride alloys using bowing parameter (used as fitting parameter ${ }^{19-22}$ ) whereas in the present work interpolation of lattice constant of binary nitride alloys has been used along with alloy-disorder effect under VCA, to calculate the accurate lattice parameter of ternary alloy ${ }^{19-22}$. 


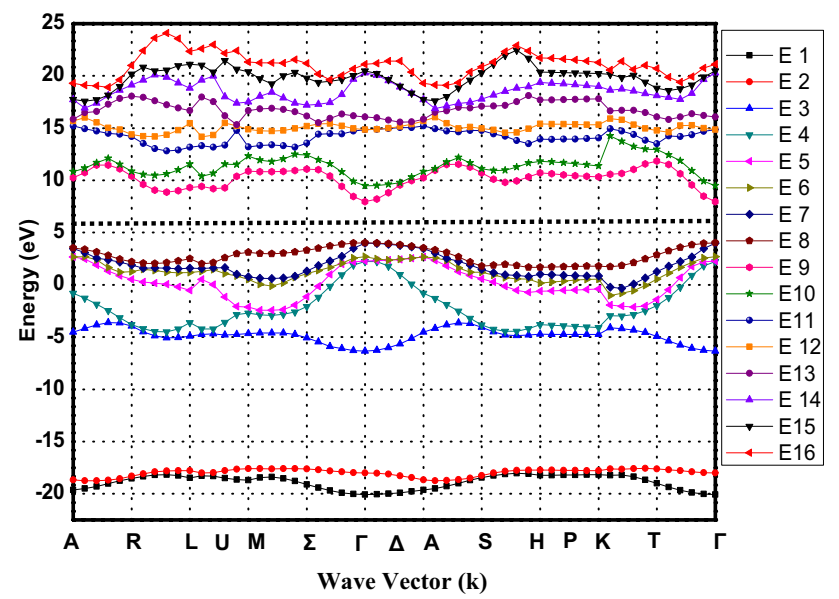

Figure 1. Full electronic band structure of $\mathrm{Al}_{0.2} \mathrm{Ga}_{0.8} \mathrm{~N}$ at $300 \mathrm{~K}$ simulated by empirical pseudopotential method using virtual crystal approximation.

\begin{tabular}{|l|l|l|l|l|l|l|l|}
\hline Material & $\begin{array}{l}\text { Previously reported } \\
\text { values of } \mathrm{E}_{\mathrm{g}}\end{array}$ & $\mathbf{E}^{\mathrm{LDA}}$ & $\mathbf{E}^{\mathrm{LDA}-1 / 2}$ & DFT $^{\mathrm{PBE}}$ & DFT $^{\mathrm{HSE}}$ & Experiments & $\mathbf{E}^{\text {This work }}$ \\
\hline $\mathrm{AlN}$ & $6.54^{7}, 6.23^{10}$ & $4.50^{5,7}$ & $6.06^{5}$ & $4.13^{7}, 4.02^{20}$ & $6.42^{7}, 6.29^{20}$ & $6.23^{5}, 6.026^{17}, 6.1-6.2^{7,20}$ & 6.20 \\
\hline $\mathrm{GaN}$ & $3.5^{7}, 3.507^{10}$ & $2.02^{5}, 2.11^{7}$ & $3.52^{5}$ & $1.69^{7,20}$ & $3.55^{7}, 3.55^{20}$ & $3.507^{5}, 3.35^{22}, 3.51^{20}$ & 3.47 \\
\hline $\mathrm{InN}$ & $0.7-1.0^{7,8}, 0.7-1.9^{10}$ & $-0.03^{5},-0.24^{7}$ & $0.95^{5}$ & $-0.42^{7,20}$ & $0.86^{7}, 0.86^{20}$ & $0.7-1.9^{5}, 0.6-0.7^{20}$ & 0.7 \\
\hline $\mathrm{Al}_{0.2} \mathrm{Ga}_{0.8} \mathrm{~N}$ & $3.99^{*}$ & $2.353^{5}$ & $3.951^{5}$ & $4.570^{12}$ & $4.569^{12}$ & $3.962^{24}$ & 3.94 \\
\hline $\mathrm{In}_{0.2} \mathrm{Ga}_{0.8} \mathrm{~N}$ & $2.72-2.78^{*}$ & $1.52^{5}$ & $2.76^{5}$ & $2.272^{5}$ & $1.925^{12}$ & $2.625^{23}$ & 2.66 \\
\hline $\mathrm{In}_{0.2} \mathrm{Al}_{0.8} \mathrm{~N}$ & $4.7-4.76^{*}$ & $3.431^{5}$ & $4.409^{5}$ & $3.445^{12}$ & $2.976^{12}$ & $4.515^{25}$ & 4.71 \\
\hline
\end{tabular}

Table 3. Energy difference $E_{g}=\left(\Gamma_{8}^{\mathrm{v}}-\Gamma_{1}^{\mathrm{c}}\right)$ obtained using FullBand simulator based on the proposed model compared with those reported earlier, with those computed from previously reported various density functional theory (DFT) techniques and with experimental results. Here suffix represents the reference numbers. $L D A$ local density approximation, $L D A-1 / 2$ approximately includes the self-energy of excitations in semiconductors, $P B E$ Perdew-Burke-Ernzerhof (PBE) exchange energy theory, HSE Heyd-Scuseria-Ernzerhof exchange-correlation functional uses an error function screened Coulomb potential to calculate the exchange portion of the energy. ${ }^{*}$ calculated from modified Vegard's law ${ }^{11,12}$ $\mathrm{E}_{\mathrm{g}}(\mathrm{x})=\mathrm{x} \cdot \mathrm{E}_{\mathrm{g}}^{\mathrm{A}}+(1-\mathrm{x}) \cdot \mathrm{E}_{\mathrm{g}}^{\mathrm{B}}-\mathrm{b} \cdot \mathrm{x} .(1-\mathrm{x})$ where $\mathrm{A}$ and $\mathrm{B}$ represent band gap values for binary nitride alloys and $\mathrm{b}$ is bowing parameter ${ }^{12}$.

For brevity, we have depicted only $\mathrm{Al}_{0.2} \mathrm{Ga}_{0.8} \mathrm{~N}$ full band structure here in Fig. 1. To better validate the accuracy of proposed empirical pseudopotential method inbuilt in FullBand simulator ${ }^{15}$, used for the full band structure simulation in current manuscript, the authors have compared and contrasted the energy values $\Gamma_{8}^{\mathrm{v}}$, and $\Gamma_{1}^{\mathrm{c}}$ at gamma valley with previously reported experimental data taken from references ${ }^{5,23-27}$. Band gaps for AlN, GaN, InN, and $\mathrm{Al}_{0.2} \mathrm{Ga}_{0.8} \mathrm{~N}, \mathrm{In}_{0.2} \mathrm{Al}_{0.8} \mathrm{~N}$ and $\mathrm{In}_{0.2} \mathrm{Ga}_{0.8} \mathrm{~N}$ alloys are also compared with the results obtained by various density functional theories including $\mathrm{LDA}^{5,7,28}$, LDA-1/2 ${ }^{5}, \mathrm{PBE}^{7,12,28}$ and $\mathrm{HSE}^{7,12,28}$ methods. All the comparison data are tabulated in Table 3. The comparison reflects that our bandgap results for binary and ternary group-III nitrides are much closer to the experimental results and superior to the bandgap results obtained on basis of various DFT based approaches.

The carrier transport on three valleys in ElecMob simulator are described by solution of Boltzmann transport equation (BTE) under non-equilibrium conditions due to applied external forces including rate change of distribution function. The Monte Carlo program implemented in ElecMob simulator for simulation of carrier transport process is initiated with carriers under equilibrium conditions, the first free flight duration is chosen with a probability distribution determined by the scattering probabilities under external electrostatic force. The force on each particle in real space is related to the E-k dispersion relation obtained with full band structure. Contribution of magnetic field $\mathrm{B}$ is taken as zero i.e. $\mathrm{B}=0$ in the present model $^{29,30}$.

$$
\begin{gathered}
v=\frac{1}{\hbar} \frac{d E}{d k} \\
\mathrm{k}(\mathrm{t})=\mathrm{k}(0)-\frac{\mathrm{e}(\varepsilon) \mathrm{t}}{\hbar}
\end{gathered}
$$




\begin{tabular}{|c|c|c|c|c|c|c|}
\hline Parameters & GaN & AlN & InN & $\mathrm{Al}_{0.2} \mathrm{Ga}_{0.8} \mathrm{~N}$ & $\mathrm{In}_{0.2} \mathrm{Ga}_{0.8} \mathrm{~N}$ & $\mathrm{In}_{0.2} \mathrm{Al}_{0.8} \mathrm{~N}$ \\
\hline $\mathrm{M}\left(\mathrm{kg} / \mathrm{m}^{3}\right)$ & 6087 & 3230 & 6240 & 5515.6 & 6117.6 & 3832 \\
\hline $\mathrm{v}_{\mathrm{s}}(\mathrm{m} / \mathrm{s})$ & 7619 & 9060 & 3780 & 7907 & 6851.2 & 8004 \\
\hline $\mathrm{D}_{\mathrm{a}}(\mathrm{eV})$ & 8.3 & 6.2 & 4.76 & 7.88 & 7.05 & 5.37 \\
\hline$\varepsilon_{s}$ & 9.7 & 8.5 & 15.3 & 9.46 & 10.82 & 9.86 \\
\hline$\varepsilon_{\infty}$ & 5.28 & 4.77 & 8.4 & 5.18 & 5.904 & 5.496 \\
\hline$m_{\Gamma}$ & 0.2 & 0.48 & 0.04 & 0.256 & 0.168 & 0.392 \\
\hline$m_{\mathrm{U}}$ & 0.4 & 1 & 0.25 & 0.52 & 0.53 & 0.85 \\
\hline $\mathrm{m}_{\Gamma_{3}}$ & 0.6 & 1 & 1 & 0.68 & 0.52 & 1 \\
\hline$U-\Gamma(\mathrm{eV})$ & 1.34 & 0.7 & 2.71 & 1.21 & 1.614 & 1.01 \\
\hline$\Gamma_{3}-\Gamma(\mathrm{eV})$ & 2.14 & 1.0 & 1.78 & 1.91 & 2.068 & 1.156 \\
\hline \multicolumn{7}{|c|}{ Equivalent valleys } \\
\hline$\Gamma$ & \multicolumn{6}{|l|}{1} \\
\hline $\mathrm{U}$ & \multicolumn{6}{|l|}{6} \\
\hline$\Gamma_{3}$ & \multicolumn{6}{|l|}{1} \\
\hline$\hbar \omega_{L O}(\mathrm{meV})$ & 0.091 & 0.099 & 0.073 & 0.093 & 0.087 & 0.094 \\
\hline$D_{i j}\left(\mathrm{eV} \mathrm{m}^{-1}\right)$ & \multicolumn{6}{|l|}{$10^{11}$} \\
\hline$\hbar \omega_{i j}(\mathrm{meV})$ & 0.073 & 0.099 & 0.029 & 0.078 & 0.06 & 0.085 \\
\hline \multicolumn{7}{|c|}{$\alpha\left(\mathrm{eV}^{-1}\right)$ Nonparaboli-city } \\
\hline$\Gamma$ & 0.19 & 0.04 & 1.32 & 1.16 & 0.42 & 0.299 \\
\hline $\mathrm{U}$ & 0.03 & 0 & 0.23 & 0.06 & 0.07 & 0.046 \\
\hline$\Gamma_{3}$ & 0.08 & 0 & 0 & 0.023 & 0.061 & 0.0 \\
\hline$P_{z}\left(\mathrm{C} / \mathrm{m}^{2}\right)$ & 0.38 & 0.92 & 0.38 & 0.48 & 0.38 & 0.811 \\
\hline
\end{tabular}

Table 4. Material parameters used for mole fraction $\mathrm{x}=0.2$ in our Monte Carlo simulation. M: mass density $v_{s}$ : Sound velocity, $D_{a}$ : acoustic deformation potential, $\varepsilon_{s}$ : static dielectric constant, $\varepsilon_{\infty}$ : High Frequency dielectric constant, $D_{i j}$ : Intervalley Deformation Potentials, $\alpha$ : non-parabolicity factor and $P_{z}$ : piezoelectric constant are taken from reference ${ }^{10,11} . \mathrm{m}_{\mathrm{r}}$ : Effective mass at $\Gamma$ valley, $\mathrm{m}_{\mathrm{U}}$ : Effective mass at $\mathrm{U}$ valley, $\mathrm{m}_{\mathrm{r} 3}$ : Effective mass at $\Gamma_{3}$ valley, $U-\Gamma, \Gamma_{3}-\Gamma$ are valley separation, $\hbar \omega_{L O}$ : Optical Phonon energies, $\hbar \omega_{i j}$ : Intervalley Phonon Energies are extracted from the E-k data obtained through FullBand simulator.

Here $\mathrm{k}$ is the time dependent wave vector, $\hbar$ is Planck's constant, e and $\varepsilon$ are the electronic charge and external applied field respectively.

The electron-lattice, electron-electron and electron-defect coupling strengths are important physical quantities dictating the interactions of the electron with lattice and with extrinsic defect. These interactions are responsible for relaxing momentum and the energy of the electrons, and are included in terms of different scattering probabilities in the simulation program. Scattering rates are strongly dependent on the electronic structure. Density of states in particular valley at particular time plays important role in deciding the probability of scattering events which follow the energy conservation principle i.e. Fermi Golden rule.

All physical quantities of interest, e.g. velocity, energy associated with electron are recorded for the free flight of carriers. The free flight of carriers is interrupted by any one of the scattering processes and scattered electron goes into new $\mathrm{k}$ state which is randomly chosen as initial state for next free flight under repeated iterative scheme. It is found that the accuracy of calculated results depends on the precision in time scale for iteration.

\section{Results and discussion}

This section concentrates on the results obtained regarding specific aspects of electron mobility investigated using the model proposed in this paper, which is based on wide band gap nitride alloys, under various operating conditions. Full band structure of $\mathrm{Al}_{0.2} \mathrm{Ga}_{0.8} \mathrm{~N}$ has been shown here in Fig. 1 . At normal pressure in wurtzite structure four atoms exist in the unit cell which produces eight valence bands. The projected density of states (per unit energy) and carrier effective masses at different valleys have been extracted from full band structure (not shown here) using energy-wavevector (E-k) data. In $\mathrm{Al}_{0.2} \mathrm{Ga}_{0.8} \mathrm{~N}$ full band structure, bands 1 and 2 show strong s-like character and rest of the bands exhibit p-like character, Fig. 1. Especially bands 6 and 8 illustrate pure pxy-like and pz-like characters respectively. The primary valley for all materials lies at $\Gamma_{\mathrm{c}}^{1}$. The secondary valleys included in the simulation are located at $U$ and $\Gamma_{c}^{3}$. It should be noted that their relative energy ordering varies among the materials studied here-GaN, AlN, InN, $\mathrm{Al}_{0.2} \mathrm{Ga}_{0.8} \mathrm{~N}, \mathrm{In}_{0.2} \mathrm{Ga}_{0.8} \mathrm{~N}$ and $\operatorname{In}_{0.2} \mathrm{Al}_{0.8} \mathrm{~N}$. The U-valley minima are assumed at the midpoint between the $\mathrm{M}$ and $\mathrm{L}$ symmetry points, with six equivalent valleys. The extracted band parameters for the six binary and ternary nitride alloys are given in Table 4.

Such structures have been obtained for all the other alloys considered here. The accuracy of simulated band gap results obtained from FullBand simulator is tested against experimental results and also compared against results obtained with various DFT based approaches. Our extracted bandgap results show excellent agreement with the experimental results as compared to the DFT-LDA, DFT-PBE and DFT-HSE results which are clearly reflected from Table 3. The outcome of electron transport on three valleys over electronic band structure using 


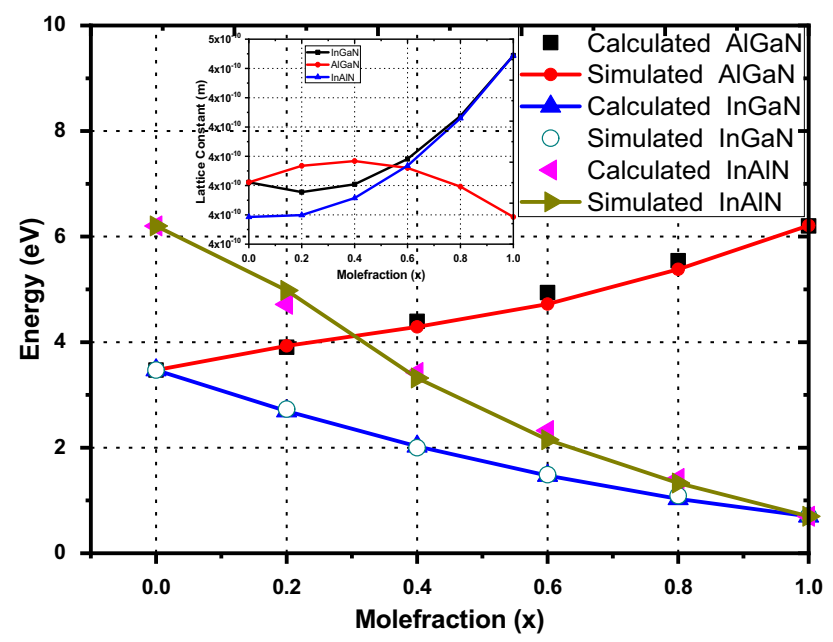

Figure 2. Energy gap as a function of mole fraction $x$ for ternary alloys and comparison with calculated results based on Vegard's law using reported bowing parameters ${ }^{11}$. Satellite Figure represents variation of lattice constant of ternary alloys with mole fraction ' $\mathrm{x}$ '.

\begin{tabular}{|c|c|c|c|c|c|c|c|c|}
\hline \multirow[b]{3}{*}{ Material } & \multirow{2}{*}{\multicolumn{2}{|c|}{\begin{tabular}{|l|} 
Without $P_{s}$ \\
$N_{d}=10^{22} \mathrm{~m}^{-3}$ \\
\end{tabular}}} & \multicolumn{6}{|c|}{ With Piezoelectric Scattering $\left(P_{s}\right)$} \\
\hline & & & \multicolumn{2}{|c|}{$\mathrm{N}_{\mathrm{d}}=10^{21} \mathrm{~m}^{-3}$} & \multicolumn{2}{|c|}{$\mathrm{N}_{\mathrm{d}}=10^{22} \mathrm{~m}^{-3}$} & \multicolumn{2}{|c|}{$N_{d}=10^{23} \mathrm{~m}^{-3}$} \\
\hline & $\mathbf{v}_{\mathrm{d}(\mathrm{sat})}$ & $\varepsilon$ & $\mathbf{v}_{\mathrm{d}(\mathrm{sat})}$ & $\varepsilon$ & $\mathbf{v}_{\mathrm{d}(\text { sat })}$ & $\varepsilon$ & $\mathbf{v}_{\mathrm{d}(\text { sat })}$ & $\varepsilon$ \\
\hline GaN & $338,241.76$ & 240 & $332,702.11$ & 260 & $336,347.62$ & 240 & $335,330.14$ & 240 \\
\hline AlN & $175,340.32$ & 420 & $165,126.54$ & 480 & $165,357.21$ & 480 & $164,567.43$ & 500 \\
\hline $\mathrm{InN}$ & $495,755.11$ & 40 & $468,867.88$ & 60 & $468,405.97$ & 60 & $467,559.28$ & 60 \\
\hline $\mathrm{Al}_{0.2} \mathrm{Ga}_{0.8} \mathrm{~N}$ & $305,409.52$ & 300 & $300,118.99$ & 320 & $300,042.37$ & 320 & $300,383.95$ & 320 \\
\hline $\mathrm{Al}_{0.4} \mathrm{Ga}_{0.6} \mathrm{~N}$ & $282,982.04$ & 360 & $277,402.67$ & 360 & $276,870.74$ & 360 & $276,513.34$ & 380 \\
\hline $\mathrm{In}_{0.2} \mathrm{Ga}_{0.8} \mathrm{~N}$ & $328,157.22$ & 220 & $323,701.12$ & 220 & $323,543.69$ & 220 & $322,908.79$ & 240 \\
\hline $\mathrm{In}_{0.4} \mathrm{Ga}_{0.6} \mathrm{~N}$ & $332,536.42$ & 180 & $326,761.45$ & 180 & $326,562.54$ & 200 & $325,739.35$ & 200 \\
\hline $\mathrm{In}_{0.2} \mathrm{Al}_{0.8} \mathrm{~N}$ & $228,558.30$ & 540 & $219,712.81$ & 580 & $219,936.09$ & 580 & $217,867.01$ & 540 \\
\hline $\mathrm{In}_{0.4} \mathrm{Al}_{0.6} \mathrm{~N}$ & $230,890.69$ & 440 & $221,966.17$ & 480 & $221,816.73$ & 480 & $221,207.67$ & 460 \\
\hline
\end{tabular}

Table 5. The comparison of 'peak electron drift velocities $\mathrm{v}_{\mathrm{d}(\mathrm{sat})}$ occurring at certain applied electric field. $\varepsilon$ ' for various doping densities at room temperature $300 \mathrm{~K}$ under piezoelectric scattering mechanism off and on. The ratio of $\mathrm{v}_{\mathrm{d}(\text { sat })}$ to $\varepsilon$ gives the mobility.

Monte Carlo technique has been tabulated for binary and ternary group-III nitrides, however for brevity we have shown only few graphical results i.e. at ambient temperature $300 \mathrm{~K}$ and doping dose $10^{22} \mathrm{~m}^{-3}$. Further, on the basis of results, a generalized innovative mobility model formulation is underway for all binary and ternary III-V nitride alloys.

The comparison of the variation of simulated-energy gaps with previously reported values of energy gaps calculated using modified Vegard's law ${ }^{19-22}$, as a function of mole fraction $\mathrm{x}$ for ternary nitride alloys is also shown in Table 3 and Fig. 2. Our simulated-energy gap as a function of mole fraction exhibits good agreement, with the results reported in literature ${ }^{19-22}$. Different values of the bowing parameter for a particular ternary nitride alloy are reported in literature for fitting the energy gap values ${ }^{5,31}$. In current analysis, alloy disorder effect along with, Table 2, under virtual crystal approximation is used to interpolate the lattice constant binary alloys to obtain the lattice constant of ternary alloys which subsequently leads to determination of energy gaps. The increasing degree of disorder causing the translational symmetry breaking and pronounced carrier localization, is included in the determined lattice parameter of ternary alloy and used in the FullBand simulator to determine the energy band gaps ${ }^{32}$. Variation of lattice parameter of the ternary nitride alloys with mole fraction ' $x$ ' is of parabolic nature as shown in the inset of Fig. $2 . \mathrm{In}_{0.2} \mathrm{Ga}_{0.8} \mathrm{~N}$ and $\operatorname{In}_{0.2} \mathrm{Al}_{0.8} \mathrm{~N}$ show small variation in lattice constant up to $4 \%$ Indium content beyond which the lattice constant increases sharply. For $\mathrm{Al}_{0.2} \mathrm{Ga}_{0.8} \mathrm{~N}$ the behavior is inverse to that exhibited by the In-based ternary alloys. The optimum alloy disorder parameters used in present analysis are listed in Table 2. The extracted band parameters $-\varepsilon_{\mathrm{s}} \varepsilon_{\infty} \mathrm{m}_{\Gamma} \mathrm{m}_{\mathrm{U}} \mathrm{m}_{\Gamma 3}, \mathrm{U}-\Gamma, \Gamma_{3}-\Gamma, \Gamma, \mathrm{U}, \Gamma_{3}, \hbar \omega_{\mathrm{LO}}$, $\hbar \omega_{\mathrm{ij}}$ and $\alpha-$ from full band structure of each binary and ternary nitride alloys, are given in Table 4 . However, the full band structure of $\mathrm{Al}_{0.2} \mathrm{Ga}_{0.8} \mathrm{~N}$ only is shown here.

The computation of electron drift velocity at different temperatures and various doping densities have been carried out on three valleys of full band structure. However data at room temperature only is given in Table 5. 


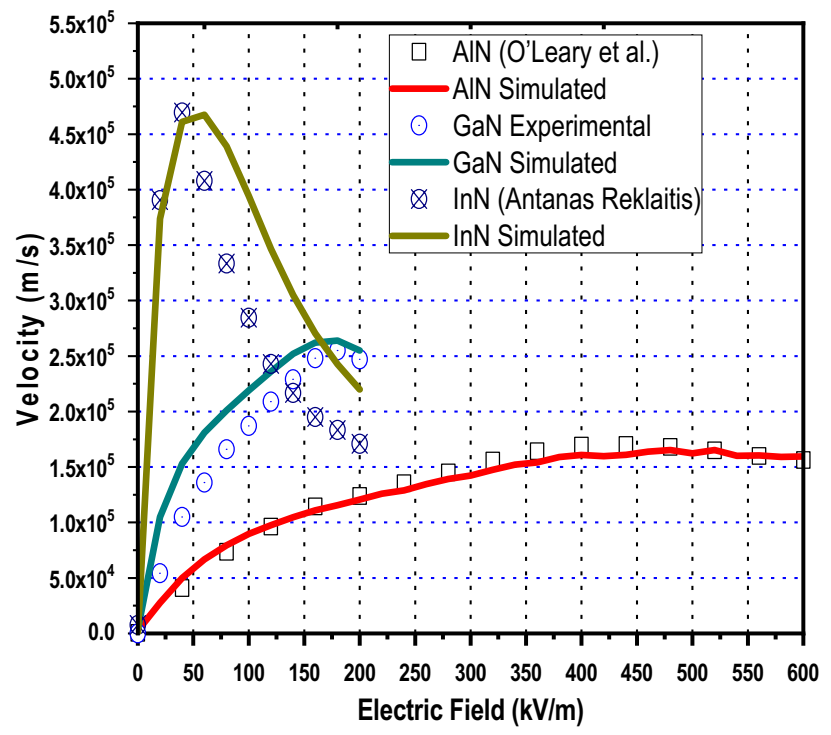

Figure 3. The Comparison of simulated electron drift velocity as a function of applied electric field with the reported literature. Data from present work is displayed as solid lines where as experimental/theoretical results are depicted by open circles, squares and triangles for $\mathrm{AlN}^{33}, \mathrm{GaN}^{1}$ and $\mathrm{InN}^{34}$ respectively.

The peak values of drift velocity can be used for proposing generalized carrier mobility model for binary and ternary nitride alloys. The accuracy of the mobility model proposed in this paper has been verified against both the theoretical and experimental results reported in the literature. The model verification for $n$-type $\mathrm{GaN}^{1}, \mathrm{AlN}^{33}$ and $\mathrm{InN}^{34}$ is performed at various strengths of applied electric field, Fig. 3. The drift velocities simulated for binary nitride alloys have been compared with experimental/theoretical values reported in literature and the comparison is shown in Fig. 3. Notably, a close agreement has been found between our results and those reported in literature. Here, the highest peak-mobility $4.68 \times 10^{5} \mathrm{~m}^{2} / \mathrm{kV}-\mathrm{s}$, is obtained in InN material, at $60 \mathrm{kV} / \mathrm{m}$ electric field, Fig. 3, beyond which there is a noticeable difference between our simulated-drift-velocity and that reported by Antanas Reklaitis $^{34}$. Our reported drift-velocity values are higher and the difference is due to selection of different type of scattering phenomena-acoustic, intervalley, optical (Polar), piezoelectric, ionized impurity, Coulomb and surface roughness-as well as due to selection of the optimum band parameter-values i.e. mass density $\mathrm{M}$, sound velocity $\mathrm{v}_{\mathrm{s}}$, acoustic deformation potential $D_{a}$, intervalley deformation potentials $D_{i j}$, non-parabolicity factor $\alpha$, piezoelectric constant $P_{z}$ (Table 4) and the rest parameters extracted from the full band diagram shown in Fig. 1. The simulated-peak-velocity for $\mathrm{GaN}$ is quite close to the experimental velocity reported by Jonathan Marini et al. ${ }^{1}$, Fig. 3. Further, the drift velocity simulated by our model for AlN alloy matches exactly with the results reported by S. K. O'Leary et al. ${ }^{33}$. as shown in Fig. 3 . Thus our present mobility model justifies the results previously reported in literature. The minor differences observed in the present simulation velocity-curve and already reported experimental velocity-curves reproduced here for $\mathrm{GaN}$ and $\mathrm{InN}$ is attributed to valley separation parameters which are responsible for the intervalley electrons transfer. Our valley separation parameters have been extracted from full energy band diagram obtained using FullBand simulator. Also the electron effective mass plays significant role in deciding the intervalley transitions in terms of valley occupation factor. Thus the analysis of electron transport done here on three valleys over full band structure extracts the accurate band parameters and hence the present model is suitable for actual prediction of transportation of electrons on the band structure under external applied electric field as is seen in Fig. 3.

Therefore, using this model electron drift velocity at room temperature as a function of electric field for GaN, AlN, InN, $\mathrm{Al}_{0.2} \mathrm{Ga}_{0.8} \mathrm{~N}, \mathrm{In}_{0.2} \mathrm{Ga}_{0.8} \mathrm{~N}$, and $\mathrm{In}_{0.2} \mathrm{Al}_{0.8} \mathrm{~N}$ is displayed in Figs. 4 and 5. The simulated-velocity curves shown in Fig. 3 for model calibration purpose are included in Fig. 5. The drift velocity associated with different nitride alloys is simulated by considering the maximum piezoelectric scattering rate at varying doping densities and different operating temperatures. The simulation data for peak-drift velocity along with the corresponding applied electric field strength $\varepsilon$ under various operating conditions are tabulated in Table 5. The effect of piezoelectric scattering on drift velocity has been analyzed by removing the terms representing piezoelectric scattering from the present model. The drift velocity values in the absence and in the presence of piezoelectric scattering are illustrated in Figs. 4 and 5 respectively. With a doping density of $10^{22} \mathrm{~m}^{-3}$ and absence of piezoelectric scattering, the peak-drift-velocity values come out to be $338,241.76,175,340.32,495,755.11,305,409.52,282,982.04$, $328,157.22,332,536.42,228,558.30$ and 230,890.69 m/s for GaN, AlN, InN, $\mathrm{Al}_{0.2} \mathrm{Ga}_{0.8} \mathrm{~N}, \mathrm{Al}_{0.4} \mathrm{Ga}_{0.6} \mathrm{~N}, \mathrm{In}_{0.2} \mathrm{Ga}_{0.8} \mathrm{~N}$, $\mathrm{In}_{0.4} \mathrm{Ga}_{0.6} \mathrm{~N}, \mathrm{In}_{0.2} \mathrm{Al}_{0.8} \mathrm{~N}$ and $\mathrm{In}_{0.4} \mathrm{Al}_{0.6} \mathrm{~N}$ respectively, which are comparatively higher than the corresponding values in presence of piezoelectric scattering, as expected. Also the peak-drift-velocities occur at comparatively lower applied field strengths, Table 5. This prominent difference, due to absence of piezoelectric scattering mechanism, is observed in all nitride alloys. As can also be seen from Fig. 4 the peak-drift-velocity increases in magnitude and shifts to left side i.e. towards lower applied electric field, when piezoelectric scattering is absent over the three valleys. Maximum variation in drift velocity is found in $\mathrm{InN}$ and its composite alloys, due to high piezoelectric 


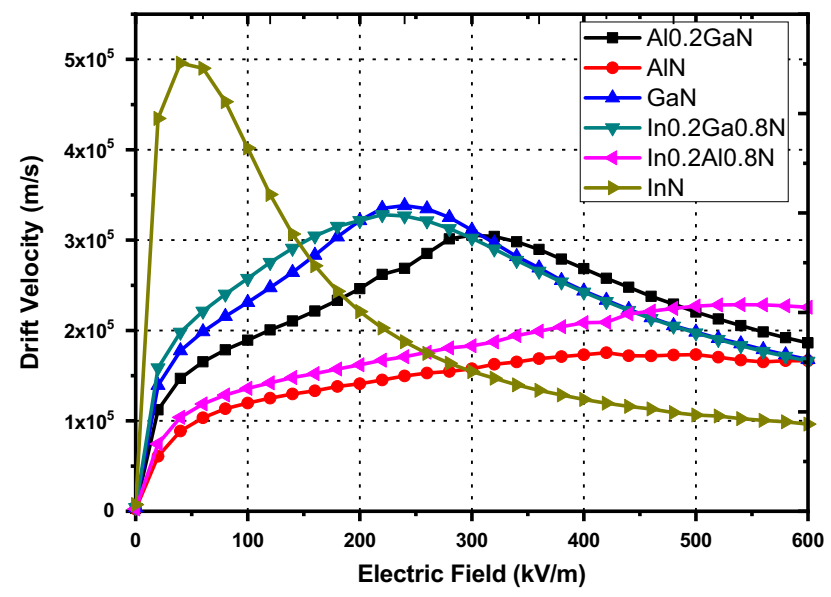

Figure 4. Carrier drift velocity with respect to the electric field $(\mathrm{kV} / \mathrm{m})$ of binary and ternary alloys without piezoelectric Scattering and doping density $10^{22} \mathrm{~m}^{-3}$ at $300 \mathrm{~K}$.

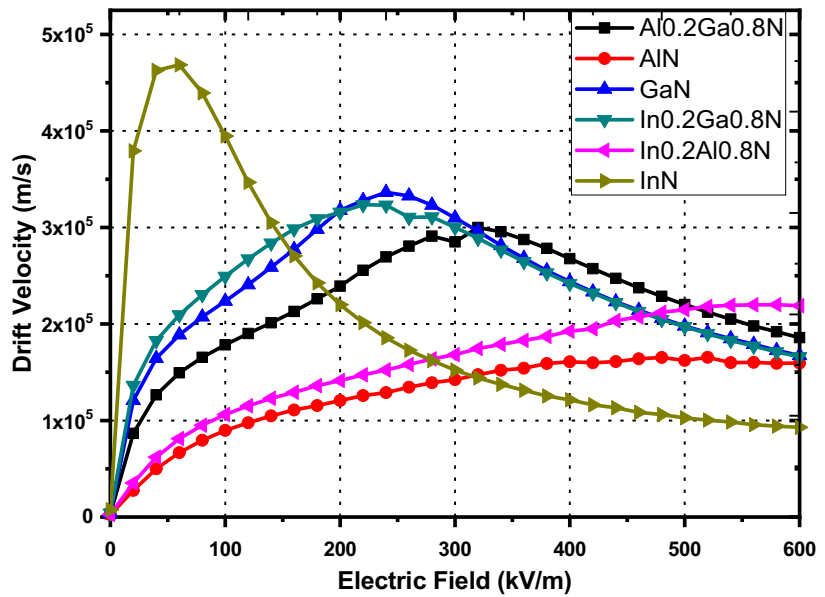

Figure 5. Carrier drift velocity using the model presented here, with respect to the electric field $(\mathrm{kV} / \mathrm{m})$ of binary and ternary alloys with piezoelectric Scattering and doping density $10^{22} \mathrm{~m}^{-3}$ at $300 \mathrm{~K}$.

scattering rate, which is also evident from Table 5. When piezoelectric scattering term is taken into account and the doping density is taken as $10^{22} \mathrm{~m}^{-3}$, again the highest peak-drift-velocity is exhibited by InN and at a much lower electric field as compared to other nitride alloys, Fig. 5. This study proves that piezoelectric scattering effect can provide useful details of physical effects inside responsible for degradation of electron mobility and could be minimized through application of reverse piezoelectric effect in the films through application of appropriate electric field. A close look at Figs. 4 and 5 clearly demonstrates the fact for InN and GaN. The analysis proposed by Jin Zhang ${ }^{35}$ also confirms that under the influence of external electric field the Young's modulus of GaN monolayer changes, thus changing the phonon group velocity. It was found that the applied field induces inplane stress in the monolayer $\mathrm{GaN}$ due to the inverse piezoelectric effect. It changes the lattice anharmonicity as well as affects the phonon mean free path. The in-plane stress may generate the buckling instability in long GaN monolayers and significantly reduce the phonon mean free path.

The effect of separate scattering mechanisms on the carrier drift velocity with respect to applied electric field is shown in Fig. $6 \mathrm{a}-\mathrm{f}$ for doping density $10^{22} \mathrm{~m}^{-3}$ at $300 \mathrm{~K}$ for binary and ternary group-III nitrides. The initial variation of electron drift velocity for each scattering mechanism shows linear dependence on applied electric field followed by state of saturation resulting in constant drift velocity for increasing electric field. The saturated drift velocity justifies the maximum valley occupation of electrons and intervalley transfer of electrons. All the scattering mechanisms show similar trend except polar optical scattering which depicts the nonlinear behavior. The nonlinear behavior can be explained through change in energy and mass of carrier after polar optical scattering event take place. At a given temperature T, the polar optical scattering will be as large as $\hbar \omega_{\mathrm{LO}}$ and is close to $\mathrm{K}_{\mathrm{B}} \mathrm{T}$. On the other hand, the polar optical scattering dependence on the square root of the effective mass is easy to understand ${ }^{2}$, since the interaction with the long-range field associated to longitudinal phonon modes must grow with the electron localization, and thus with the mass. When $\mathrm{E}<\hbar \omega_{\mathrm{LO}}$, only absorption of $\hbar \omega_{\mathrm{LO}}$ phonons is possible; when E comes across $\hbar \omega_{\mathrm{LO}}$, carriers can absorb and emit, thus polar optical scattering is suddenly suppressed; finally, when $\mathrm{E} \gg \hbar \omega_{\mathrm{LO}}$ the scattering probability becomes more and more unlikely and 

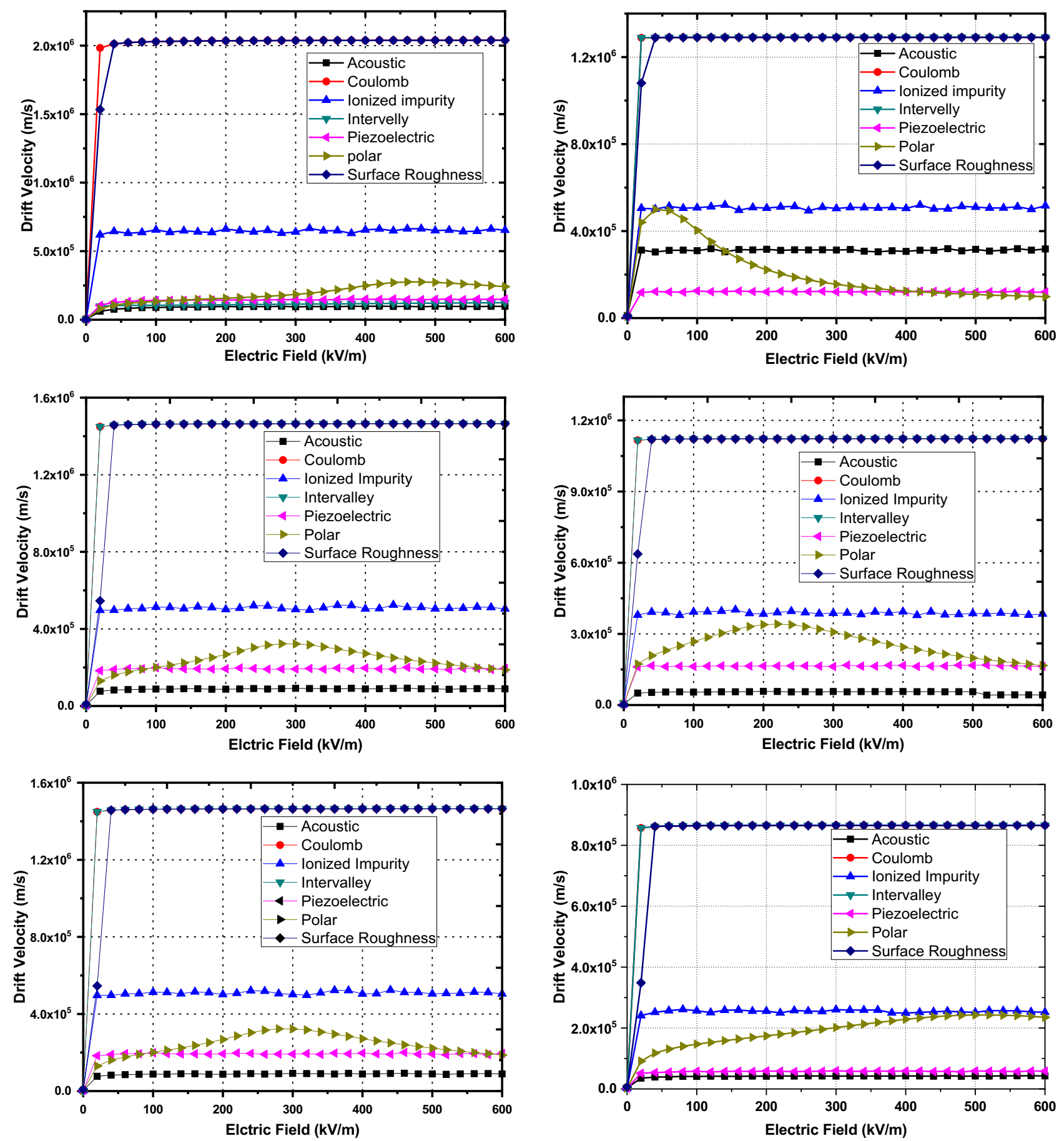

Figure 6. (a) AlN alloy Carrier drift velocity with respect to electric field (E) with separate scattering mechanisms and doping density $1022 \mathrm{~m}^{-3}$ at $300 \mathrm{~K}$. (b) $\mathrm{GaN}$ alloy Carrier drift velocity with respect to electric field (E) with separate scattering mechanisms and doping density $1022 \mathrm{~m}^{-3}$ at $300 \mathrm{~K}$. (c) InN alloy Carrier drift velocity with respect to electric field (E) with separate scattering mechanisms and doping density 1022 at $300 \mathrm{~K}$. (d) Al0.2Ga0.8N alloy Carrier drift velocity with respect to Electric Field (E) with separate scattering mechanisms and doping density $1022 \mathrm{~m}^{-3}$ at $300 \mathrm{~K}$. (e) In $0.2 \mathrm{Ga} 0.8 \mathrm{~N}$ alloy Carrier drift velocity with respect to Electric Field (E) with separate scattering mechanisms and doping density $1022 \mathrm{~m}^{-3}$ at $300 \mathrm{~K}$. (f) In $0.2 \mathrm{Al} 0.8 \mathrm{~N}$ alloy Carrier drift velocity with respect to Electric Field (E) with separate scattering mechanisms and doping density $1022 \mathrm{~m}^{-3}$ at $300 \mathrm{~K}$.

polar optical scattering rate increases. It is clearly seen from Fig. 6 that polarization Coulomb field (PCF) scattering along with acoustic and intervalley scatterings is the dominant scattering mechanism and responsible for low electron mobility. The nonlinear behavior of polar optical scattering mechanism also tends to reduce 


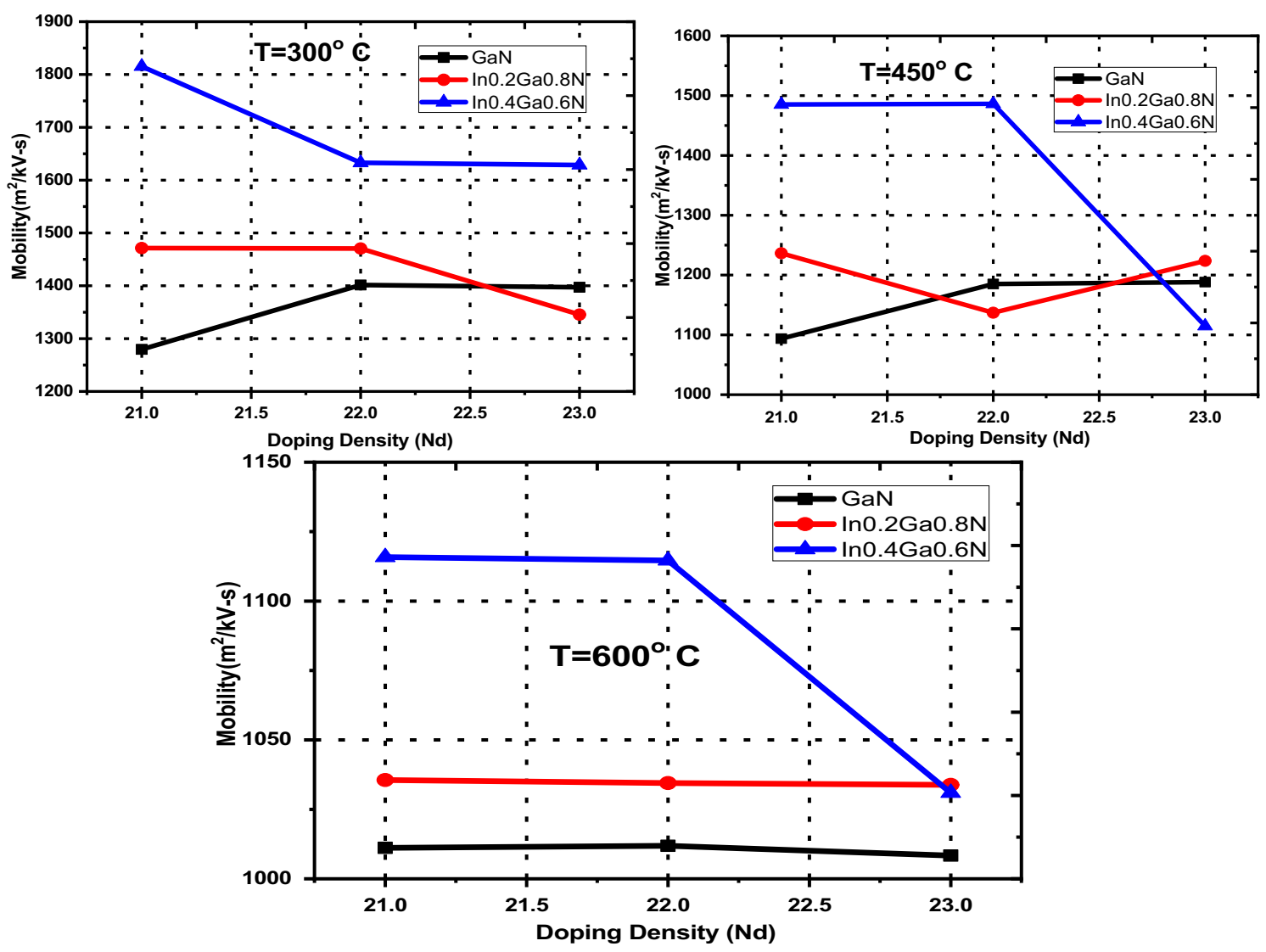

Figure 7. The variation of carrier mobility in $\mathrm{GaN}$ and $\operatorname{In}_{\mathrm{x}} \mathrm{Ga}_{1-\mathrm{x}} \mathrm{N}$ (for $\mathrm{x}=0.2$ and $\mathrm{x}=0.4$ ) with variation of doping density $\mathrm{N}_{\mathrm{d}}\left(\mathrm{m}^{-3}\right)$ at temperatures 300,450 and $600 \mathrm{~K}$ using Table 6.

the electron mobility. The effect of ionized impurity and surface roughness scatterings on the electron mobility is found to have negligible impact. The piezoelectric Coulomb field scattering has a stronger influence on the electron transport in all binary and ternary alloys.

The relation between electron mobility, the ratio of drift velocity to applied electric field, and doping density at different temperatures $(300,450$ and $600 \mathrm{~K})$ shows nonlinear variation due to dominant piezoelectric Coulomb field scattering in the lowest valley, $\Gamma$, along with different behavior for the various nitride alloys studied here, Fig. 7. This electron mobility is also dependent on the energy separation between lowest and other secondary valleys i.e. $\mathrm{U}, \Gamma_{3}$, as depicted in Table 6.

Regarding mobility in ternary nitride alloys the mole fraction $\mathrm{x}$ also plays important role. On changing $\mathrm{x}$, from 0 to 1 i.e. at extreme values of $x$, ideally the mobility should follow the behavior of binary alloys but the results obtained here are in contradiction indicating a nonlinear response. The nonlinear dependence is reflected in Fig. 8 as with increasing indium content in $\operatorname{In}_{x} \mathrm{Ga}_{1-x} \mathrm{~N}$ and $\operatorname{In}_{\mathrm{x}} \mathrm{Al}_{1-\mathrm{x}} \mathrm{N}$ the mobility increases whereas for increasing aluminium content in $\mathrm{Al}_{\mathrm{x}} \mathrm{Ga}_{1-\mathrm{x}} \mathrm{N}$ the mobility decreases. The behavior in mobility shown by $\mathrm{Al}_{\mathrm{x}} \mathrm{Ga}_{1-\mathrm{x}} \mathrm{N}$ in Fig. 8 is described in terms of relation between energy and mole fraction as depicted in Fig. 3. Increasing the $\mathrm{Al}$ content in $\mathrm{Al}_{\mathrm{x}} \mathrm{Ga}_{1-\mathrm{x}} \mathrm{N}$, the energy increases, while increasing In content in $\operatorname{In}_{\mathrm{x}} \mathrm{Ga}_{1-\mathrm{x}} \mathrm{N}$ and $\operatorname{In}_{\mathrm{x}} \mathrm{Al}_{1-\mathrm{x}} \mathrm{N}$, the energy decreases. The probability of scattering events increases with increase in energy values in turn degrading the mobility of carriers. The data for Fig. 8 is taken from Table 6 for $300 \mathrm{~K}$ and doping density $10^{22} \mathrm{~m}^{-3}$. It should be noted that the energy separation varies with variation in $\mathrm{x}$. The electrons mobility data for other doping densities, shown in Table 6 also exhibit nonlinear behavior.

In $\mathrm{GaN}$ alloy, carrier mobility is higher when piezoelectric scattering mechanism is absent. At low doping dose $10^{21} \mathrm{~m}^{-3}$ mobility is less, increases at moderate dose $10^{22} \mathrm{~m}^{-3}$ and again decreases for higher dose $10^{23} \mathrm{~m}^{-3}$, Table 6. In fact the binary alloy GaN's mobility trend with varying doping density should be followed by its ternary alloys, but the mobility rule observed with $\mathrm{GaN}$ is not found true for $\operatorname{In}_{\mathrm{x}} \mathrm{Ga}_{1-\mathrm{x}} \mathrm{N}$ or $\mathrm{Al}_{\mathrm{x}} \mathrm{Ga}_{1-\mathrm{x}} \mathrm{N}$. The reason is defined with the difference in energy separation values and nonlinearity effect in lowest valley. The varying effective masses of electrons in different valleys are also a deciding factor for determination of the nonlinear electron drift velocity and hence mobility in ternary nitride alloys. The other two ternary alloys with different mole fractions do not follow the similar mobility rule endorsing the nonlinear effect. At room temperature with varying doping dose, $\mathrm{Al}_{0.4} \mathrm{Ga}_{0.6} \mathrm{~N}$ shows continuous decrease in peak electron drift velocity observed at higher electric field; however in case of $\mathrm{Al}_{0.2} \mathrm{Ga}_{0.8} \mathrm{~N}$ the mobility first decreases and then increases though the variation is quite small. Moreover the peak electron drift velocity is observed at comparatively lower electric fields.

The effects of temperature on the carrier mobility for nitride alloys are estimated rigorously with the variation in doping dose and mole fraction of the ternary alloys. The electron mobility data for different alloys with 


\begin{tabular}{|c|c|c|c|c|}
\hline Materials & $N_{d}$ & $\mu_{300}$ & $\mu_{450}$ & $\mu_{600}$ \\
\hline \multirow{3}{*}{$\mathrm{GaN}$} & $10^{21}$ & 1279.62 & 1093.64 & 1011.16 \\
\hline & $10^{22}$ & 1401.45 & 1185.04 & 1011.88 \\
\hline & $10^{23}$ & 1397.21 & 1188.30 & 1008.36 \\
\hline \multirow{3}{*}{ AlN } & $10^{21}$ & 344.01 & 262.24 & 223.01 \\
\hline & $10^{22}$ & 344.49 & 282.75 & 225.32 \\
\hline & $10^{23}$ & 329.13 & 269.66 & 239.40 \\
\hline \multirow{3}{*}{ InN } & $10^{21}$ & 7814.46 & 6952.23 & 6123.57 \\
\hline & $10^{22}$ & 7806.77 & 6960.48 & 6115.73 \\
\hline & $10^{23}$ & 7792.65 & 6941.83 & 6096.48 \\
\hline \multirow{3}{*}{$\mathrm{Al}_{0.2} \mathrm{Ga}_{0.8} \mathrm{~N}$} & $10^{21}$ & 937.87 & 815.39 & 705.12 \\
\hline & $10^{22}$ & 937.63 & 864.19 & 705.67 \\
\hline & $10^{23}$ & 938.70 & 812.89 & 702.72 \\
\hline \multirow{3}{*}{$\mathrm{Al}_{0.4} \mathrm{Ga}_{0.6} \mathrm{~N}$} & $10^{21}$ & 770.56 & 639.59 & 530.68 \\
\hline & $10^{22}$ & 769.08 & 602.41 & 556.00 \\
\hline & $10^{23}$ & 727.67 & 638.49 & 529.72 \\
\hline \multirow{3}{*}{$\mathrm{In}_{0.2} \mathrm{Ga}_{0.8} \mathrm{~N}$} & $10^{21}$ & 1471.37 & 1236.37 & 1035.57 \\
\hline & $10^{22}$ & 1470.65 & 1136.97 & 1034.46 \\
\hline & $10^{23}$ & 1345.45 & 1223.68 & 1033.84 \\
\hline \multirow{3}{*}{$\mathrm{In}_{0.4} \mathrm{Ga}_{0.6} \mathrm{~N}$} & $10^{21}$ & 1815.34 & 1485.20 & 1115.84 \\
\hline & $10^{22}$ & 1632.81 & 1486.31 & 1114.59 \\
\hline & $10^{23}$ & 1628.69 & 1114.80 & 1030.95 \\
\hline \multirow{3}{*}{$\mathrm{In}_{0.2} \mathrm{Al}_{0.8} \mathrm{~N}$} & $10^{21}$ & 378.81 & 335.17 & 308.89 \\
\hline & $10^{22}$ & 379.20 & 345.14 & 300.30 \\
\hline & $10^{23}$ & 403.60 & 346.10 & 300.28 \\
\hline \multirow{3}{*}{$\mathrm{In}_{0.4} \mathrm{Al}_{0.6} \mathrm{~N}$} & $10^{21}$ & 439.44 & 403.11 & 313.53 \\
\hline & $10^{22}$ & 462.12 & 403.32 & 337.07 \\
\hline & $10^{23}$ & 480.89 & 402.52 & 313.33 \\
\hline
\end{tabular}

Table 6. The mobility data of nitride alloys with variation of doping density at different temperatures. The $\mu_{T}$ $\left(\mathrm{m}^{2} / \mathrm{kV}\right.$-s) is electron mobility with suffix representing operating temperature in Kelvin, $\mathrm{N}_{\mathrm{d}}$ is doping density $\left(\mathrm{m}^{-3}\right)$ and piezoelectric scattering is taken into account.

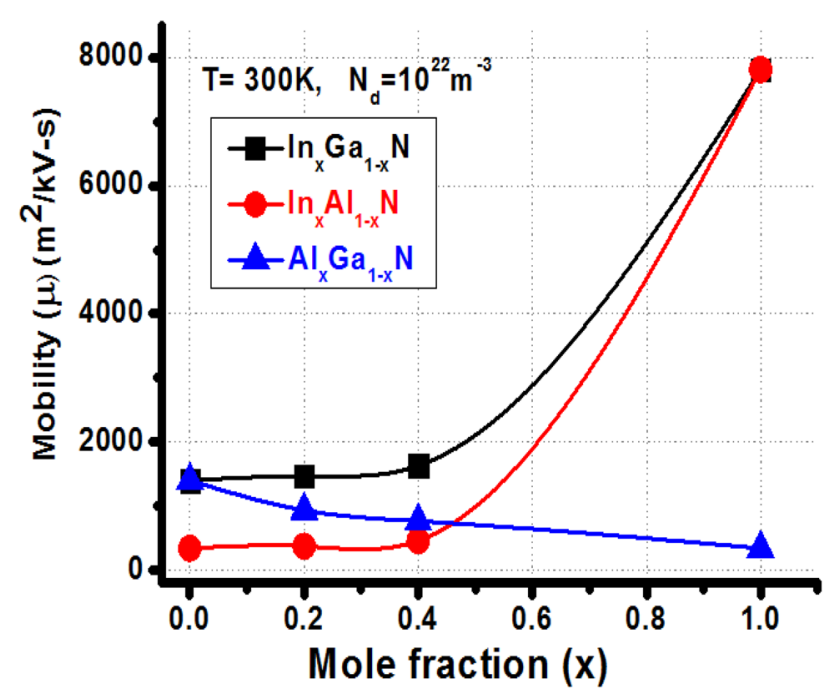

Figure 8. The carrier mobility in nitride alloys with variation of mole fraction $\mathrm{x}$ in ternary alloys at $300 \mathrm{~K}$ for doping density $10^{22} \mathrm{~m}^{-3}$ using Table 6 . T is the operating temperature and $\mathrm{N}_{\mathrm{d}}\left(\mathrm{m}^{-3}\right)$ is doping density. 
various doping densities and different operating temperatures, in Kelvin, are given in Table 6, Fig. 8. Most of the nitride alloys show decrease in mobility values with increase in operating temperature and doping density, except GaN. Its composites justify non-linear mobility effects with doping and temperature variations. The effect can be explained on the basis of energy separation and carrier dynamics over three valleys. At moderate doping $\left(10^{22} \mathrm{~m}^{-3}\right)$ and high temperature $(450 \mathrm{~K})$, the electrons scattered to U-valley and due to higher effective mass, remains in same valley. The higher mobility $\left(=7814.46 \mathrm{~m}^{2} / \mathrm{kV}-\mathrm{s}\right)$ is observed for InN alloy under low doping dose $\left(10^{21} \mathrm{~m}^{-3}\right)$ operating at room temperature $(300 \mathrm{~K})$. Increased doping dose and higher operating temperature initiate the higher scattering probabilities with higher electron energy and hence reduces the mobility.

\section{Conclusions}

Optimized Empirical Pseudopotential Method (EPM) in conjunction with Virtual Crystal Approximation (VCA) and the compositional disorder effect inbuilt in TNL's FullBand simulator is used here to extract the electronic materials parameters of wurtzite nitride alloys. The band gap results ensure excellent agreement with the experiments and show superior results over other various DFT techniques based theoretical approaches. Another beauty of this in-house developed model from FullBand simulator is that it requires only lattice constant, as input, of associated binary alloys and interpolated lattice constant of ternary nitride alloys to accurately predict the full band structure. Good agreement have been found between simulated results and experimental results reported by others regarding electron mobility of binary nitride materials $\mathrm{GaN}, \mathrm{InN}$ and AlN which is attributed to using optimized band structures and estimation of electron mobility based on different scattering mechanisms. Also the energy separation values vary with variation in $\mathrm{x}$ of ternary nitride alloys. The maximum influence of PCF scattering on binary and ternary nitride alloys are observed during electrons transport under applied electric field and is found to be responsible for mobility reduction. The nonlinear mobility behavior is noticed for GaN and its alloys. The mobility results obtained in present work indicate that electron mobility can be increased by reducing the PCF (piezoelectric and Coulomb field) scattering mechanisms. The relation between electron mobility and doping density at different temperatures, 300, 450 and $600 \mathrm{~K}$, shows nonlinear variation in the lowest valley, $\Gamma$, along with different behavior for the various nitride alloys studied here. Mobility in ternary nitride alloys varies non-linearly with the mole fraction $\mathrm{x}$. For example, at temperature $300 \mathrm{~K}$ and doping density $10^{22} \mathrm{~m}^{-3}$, increasing indium content in $\operatorname{In}_{\mathrm{x}} \mathrm{Ga}_{1-\mathrm{x}} \mathrm{N}$ and $\operatorname{In}_{\mathrm{x}} \mathrm{Al}_{1-\mathrm{x}} \mathrm{N}$ increases the mobility whereas increasing aluminium content in $\mathrm{Al}_{\mathrm{x}} \mathrm{Ga}_{1-\mathrm{x}} \mathrm{N}$ decreases the mobility. The electrons mobility data for other doping densities, considered here also exhibit nonlinear behavior. The electron mobility simulated results of each binary nitride material have been compared with experimental results under appropriate conditions and good agreement has been found between them.

Received: 10 June 2020; Accepted: 5 October 2020

Published online: 30 October 2020

\section{References}

1. Marini, J., Bell, L. D. \& Shahedipour-Sandvik, F. Monte Carlo simulation of III-nitride photocathodes. J. Appl. Phys 123, 124502 (2018).

2. Cui, P. et al. Effect of Polarization Coulomb field scattering on electrical properties of the 70-nm gate-Length AlGaN/GaN HEMTs. Sci. Rep. 8, 12850 (2018).

3. Tsai, Y.-C. \& Bayram, C. Structural and electronic properties of hexagonal and cubic phase AlGaInN alloys investigated using first principles calculations. Sci. Rep. 9, 6583 (2019).

4. Fang, J. et al. Electron transport properties of $\mathrm{Al}_{\mathrm{x}} \mathrm{Ga}_{1-\mathrm{x}} \mathrm{N} / \mathrm{GaN}$ transistors based on first-principles calculations and Boltzmannequation Monte Carlo simulations. Phys. Rev. Appl. 11, 044045 (2019).

5. Pelá, R. R. et al. Accurate band gaps of AlGaN, InGaN, and AlInN alloys calculations based on LDA-1/2 approach. Appl. Phys. Lett. 98(15), 151907 (2011).

6. Lambrecht, W. R. \& Segall, B. Anomalous band-gap behavior and phase stability of c-BN-diamond alloys. Phys. Rev. B 47, 92899296 (1993).

7. Moses, P. G., Miao, M., Yan, Q. \& Van de Walle, C. G. Hybrid functional investigations of band gaps and band alignments for AlN, GaN, InN, and InGaN. J. Chem. Phys. 134, 084703 (2011).

8. Fu-Chen, H., Ching-Tarng, L., Yia-Chung, C. \& Dallesasse, J. M. Effective bond-orbital model of III-nitride wurtzite structures based on modified interaction parameters of zinc-blende structures. Comput. Phys. Commun. https://doi.org/10.1016/j. cpc.2020.107139 (2020).

9. Oussaifi, Y. et al. Effect of pressure on the energy band gaps of wurtzite GaN and AlN and electronic properties of their ternary alloys $\mathrm{Al}_{\mathrm{x}} \mathrm{Ga}_{1-\mathrm{x}}$ N. Phys. B 407, 3604-3609 (2012).

10. Goano, M., Bellotti, E., Ghillino, E., Ghione, G. \& Brennanzz, K. F. Band structure nonlocal pseudopotential calculation of the III-nitride wurtzite phase materials system, Part I, binary compounds GaN, AlN, and InN. J. Appl. Phys. 88, 6467-6475 (2000).

11. Goano, M., Bellotti, E., Ghillino, E., Ghione, G. \& Brennanzz, K. F. Band structure nonlocal pseudopotential calculation of the III-nitride wurtzite phase materials system, Part II ternary alloys $\mathrm{Al}_{\mathrm{x}} \mathrm{Ga}_{1-\mathrm{x}} \mathrm{N}, \operatorname{In}_{\mathrm{x}} \mathrm{Ga}_{1-\mathrm{x}} \mathrm{N}$, and $\operatorname{In}_{\mathrm{x}} \mathrm{Al}_{1-\mathrm{x}} \mathrm{N}$. J. Appl. Phys. 88, 6476-6482 (2000).

12. Huang, Y. et al. Band gap and band alignment prediction of nitride based semiconductors using machine learning. J. Mater. Chem. C 7(11), 3238-3245 (2019).

13. Van de Put Maarten, L., Fischetti, M. V. \& Vandenberghe, W. G. Scalable atomistic simulations of quantum electron transport using empirical pseudopotentials. Comput. Phys. Commun. 244, 156-169 (2019).

14. Pala, M. G. \& Esseni, D. Quantum transport models based on NEGF and empirical pseudopotentials for accurate modeling of nanoscale electron devices. J. Appl. Phys. 126, 055703 (2019).

15. FullBand Simulator user manual, Tech Next Lab Private Limited https://www.technextlab.com/feb.html (2019).

16. Xiaoyu, W. \& Erez, B. Scattering mechanisms and electrical transport near an Ising nematic quantum critical point. Phys. Rev. B 99, 235136 (2019).

17. ElecMob Simulator user manual, Tech Next Lab Private Limited https://www.technextlab.com/hm.html (2019).

18. Ferreyra, R. A., Zhu, C., Teke, A. \& Morkoç, H. Group III nitrides. In Springer Handbook of Electronic and Photonic Materials (eds Kasap, S. \& Capper, P.) (Springer, Cham, 2017). 
19. Davydova, V. Y. et al. Phonon spectrum of wurtzite GaN and AlN: Experiment and theory. J. Cryst. Growth 189(190), 656-660 (1998).

20. Yeo, Y. C., Chong, T. C. \& Li, M. F. Electronic band structures and effective-mass parameters of wurtzite GaN and InN. J. Appl. Phys. 83, 1429-1436 (1998).

21. Davydov, V. Y. et al. Band gap of hexagonal InN and InGaN alloys. Phys. States Solidi (b) 234(3), 787-795 (2002).

22. Vurgaftman, I. \& Meyer, J. R. Band parameters for nitrogen-containing semiconductors. J. Appl. Phys. 94, 3675-3691 (2003).

23. Guo, Q. \& Yoshida, A. Temperature dependence of band gap change in InN and A1N. Jpn. J. Appl. Phys. 33(1), 2453-2456 (1994).

24. Drechsler, M. et al. Determination of the conduction band electron effective mass in hexagonal GaN. Jpn J. Appl. Phys. 34, L1178 (1995).

25. Yun, F. et al. Energy band bowing parameter in $\mathrm{Al}_{\mathrm{x}} \mathrm{Ga}_{1-\mathrm{x}} \mathrm{N}$ alloys. J. Appl. Phys. 92,4837 (2002).

26. O’Donnell, K. P., Fernandez-Torrente, I., Edwards, P. R. \& Martin, R. W. The composition dependence of the $\operatorname{In}_{\mathrm{x}} \mathrm{Ga}_{1-\mathrm{x}} \mathrm{N}$ bandgap. J. Cryst. Growth 269, 100 (2004).

27. Onuma, $\mathrm{T}$. et al. Recombination dynamics of localized excitons in $\mathrm{Al}_{1-\mathrm{x}} \mathrm{In}_{\mathrm{x}} \mathrm{N}$ epitaxial films on GaN templates grown by metalorganic vapor phase Epitaxy. J. Appl. Phys. 94, 2449 (2003).

28. McCluskey, M. D., Van de Walle, C. G., Master, C. P., Romano, L. T. \& Johnson, N. M. Large band gap bowing of $\operatorname{In}_{\mathrm{x}} \mathrm{Ga}_{1-\mathrm{x}} \mathrm{N}$ alloys. Appl. Phys. Lett. 72, 2725 (1998).

29. Vasileska, D. \& Goodnick, S. M. Nano-electronic Devices-Semiclassical and Quantum Transport Modeling (Springer, New York, 2011).

30. Jacoboni, C. \& Lugli, P. The Monte Carlo Method for Semiconductor Device Simulation (Springer, New York, 2019).

31. Fritsch, D., Schmidt, H. \& Grundmann, M. Band-structure pseudopotential calculation of zinc-blende and wurtzite AlN, GaN, and InN. Phys. Rev. B 67, 235205 (2003).

32. Adachi, S. In: (eds Kasap, S. \& Capper, P.) Springer Handbook of Electronic and Photonic Materials. Springer Handbooks. (Springer, Cham, 2017).

33. O'Leary, S. K., Foutzb, B. E., Shur, M. S., Bhapkar, U. V. \& Eastmanb, L. F. Monte Carlo simulation of electron transport in wurtzite aluminum nitride. Solid State Commun. 105, 621-626 (1998).

34. Reklaitis, A. Nonequilibrium optical phonon effect on high-field electron transport in InN. J. Appl. Phys. 112, 093706 (2012).

35. Zhang, J. Piezoelectric effect on the thermal conductivity of monolayer gallium nitride. J. Appl. Phys. 123, 035102 (2018).

\section{Acknowledgments}

The authors from Sanjay Gandhi Post Graduate Institute of Medical Sciences, University and University of Lucknow, acknowledge the support from Tech Next Lab Pvt Ltd (TNL) for providing access and allow to use their atomistic TNL TCAD Tools, i.e. FullBand ${ }^{\mathrm{TM}}$ and ElecMob ${ }^{\mathrm{TM}}$ simulators, computational facilities and their all financial and technical support for completing this entire work. Tech Next Lab Pvt Ltd is the original manufacturer of Family of TNL atomistic TCAD Tools.

\section{Author contributions}

A.S., A.S., P.K.S., F.K.G., P.S. and P.S. develop idea, theory and P.K.S. supervised the whole work. A.S., A.S., F.K.G., P.S., P.S., R.K.S., AS run the simulations and did the data collection. P.K.S., M.D., S.G., A.S. edited the manuscript. All authors discussed the results and commented on the manuscripts.

\section{Competing interests}

The authors declare no competing interests.

\section{Additional information \\ Correspondence and requests for materials should be addressed to A.S.}

Reprints and permissions information is available at www.nature.com/reprints.

Publisher's note Springer Nature remains neutral with regard to jurisdictional claims in published maps and institutional affiliations.

(c) (i) Open Access This article is licensed under a Creative Commons Attribution 4.0 International License, which permits use, sharing, adaptation, distribution and reproduction in any medium or format, as long as you give appropriate credit to the original author(s) and the source, provide a link to the Creative Commons licence, and indicate if changes were made. The images or other third party material in this article are included in the article's Creative Commons licence, unless indicated otherwise in a credit line to the material. If material is not included in the article's Creative Commons licence and your intended use is not permitted by statutory regulation or exceeds the permitted use, you will need to obtain permission directly from the copyright holder. To view a copy of this licence, visit http://creativecommons.org/licenses/by/4.0/.

(c) The Author(s) 2020 